\title{
An 18-GHz 300-mW SiGe Power HBT
}

\author{
Zhenqiang Ma, Ningyue Jiang, Guogong Wang, and Samuel A. Alterovitz
}

\begin{abstract}
An 18-GHz, 300-mW SiGe power heterojunction bipolar transistor (HBT) is demonstrated. The optimization of SiGe HBT vertical profile has enabled this type of devices to operate with high gain and high power at this high frequency. In the common-base configuration, a continuous wave output power of $24.73 \mathrm{dBm}$ with a power gain of $4.5 \mathrm{~dB}$ was measured from a single 20-emitter stripe $\operatorname{SiGe}\left(2 \times 30 \mu \mathrm{m}^{2}\right.$ of each emitter finger $)$ double HBT. The overall performance characteristics represent the state-of-the-art SiGe power HBTs operating in the K-band frequency range.
\end{abstract}

Index Terms-Common-base, heterojunction bipolar transistors (HBTs), SiGe.

\section{INTRODUCTION}

I N COMPARISON to III-V device technologies, a SiGe BiCMOS technology platform offers a low-cost solution for integrating RF/microwave circuits and CMOS on a single chip for future communication units. While the high-frequency performance of low-power SiGe HBTs has increased dramatically in the past few years [1], [2], high power SiGe HBTs operating at high frequencies (K-band and higher), however, have not been successfully developed. As the $20-30-\mathrm{GHz}$ frequency range is of growing interest for wireless communications, the development of SiGe power HBTs for these applications has thus reached the high-level urgency. In this letter, we report the design and performance characteristics of SiGe HBTs developed for K-band power amplifications. Under continuous wave $(\mathrm{CW})$ operation at $18 \mathrm{GHz}$, a device $\mathrm{RF}$ output power of $300 \mathrm{~mW}$ with 4.5-dB power gain has been achieved.

\section{DEVICE DESIGN AND FABRICATION}

In order to achieve a high $f_{\max }(>60-90 \mathrm{GHz})$ value for large-area SiGe power HBTs such that sufficient power gain is available in the $20-30-\mathrm{GHz}$ frequency range, while maintaining high breakdown voltages and relaxing the lithography restriction to lower the fabrication cost of these devices, the most efficient measure is to reduce the base resistance $\left(R_{B}\right)$ by increasing the base doping concentration. However, in most high-speed SiGe HBTs a low base doping concentration in conjunction with a low Ge content of a trapezoid shape is employed in order to maintain a high current gain $\beta$ (the doping profile is

Manuscript received November 30, 2004; revised March 17, 2005. This work was supported by the National Science Foundation under Grant ECS 0323717. The review of this letter was arranged by Editor E. Sangiorgi.

Z. Ma, N. Jiang, and G. Wang are with the Department of Electrical and Computer Engineering University of Wisconsin, Madison, WI 53706 USA (e-mail: mazq@engr.wisc.edu).

S. A. Alterovitz is with the NASA Glenn Research Center, Cleveland, $\mathrm{OH}$ 44135 USA.

Digital Object Identifier 10.1109/LED.2005.848619 analogous to that of traditional Si BJTs). Alternatively, the decoupling of base Gummel number from intrinsic base resistance due to SiGe induced bandgap narrowing permits a high base doping concentration (higher than emitter region) with more Ge content to be employed in the base region [3]. In this way, the reduction of current gain due to high base doping concentration can be effectively restored with a large valence band offset between emitter and base that can be obtained by incorporating a high Ge content in the base.

In addition, the high-speed characteristics (e.g., $f_{T}$ ) of highperformance SiGe HBTs are generally obtained with the sacrifice of breakdown voltages [1], [2]. In contrast to these lowbreakdown voltage devices for which emitter transit time $\tau_{E}$ is the dominant component in $\tau_{\mathrm{EC}}$, [4], [5], the collector space charge layer delay $\tau_{\mathrm{CSCL}}$ is instead the dominant time delay component in $\tau_{\mathrm{EC}}$ for high breakdown voltage $\left(\mathrm{BV}_{\mathrm{CBO}}\right) \mathrm{SiGe}$ HBTs [3]. As a result, for such high breakdown voltage SiGe HBTs, although such parameters as Ge content and Ge profile in the base region will affect $\tau_{E}$ (as well as $\tau_{B}$ ), the variation of these two parameters will not have a major influence on the $f_{T}\left(f_{T}=1 / 2 \pi \tau_{\mathrm{EC}}\right)$ values. Since $\tau_{B}$ is also not a dominant component in $\tau_{\mathrm{EC}}$ for high breakdown voltage devices, the increase of $\tau_{B}$ due to the increase of base doping concentration in the base region will have minimal impact on $\tau_{\mathrm{EC}}$ and thus on $f_{T}$. However, the reduction of $R_{B}$ resulting from a heavy base doping concentration can significantly enhance the $f_{\max }$ values without involving substantial scaling of the emitter widths. As a result, a high power gain can be achieved at higher frequencies by employing a heavily doped base region.

In the heterostructure design of the SiGe power HBTs, the collector epilayer is made thick (nominal thickness: $0.45 \mu \mathrm{m}$ ) and lightly doped $\left(3 \times 10^{16} \mathrm{~cm}^{-3}\right)$ in order to realize a high breakdown voltage. A high Ge content (24\%) with a box-shape profile is used to maintain a large valence band offset between the emitter and the base. Such a high Ge content thus permits a high doping concentration $\left(2 \times 10^{20} \mathrm{~cm}^{-3}\right)$ to be employed in a thin $(30 \mathrm{~nm})$ base region while still maintaining reasonable current gain values. In order to reduce boron outdiffusion during the chemical vapor deposition (CVD) growth and processing, 0.2 atom\% carbon was added during the epi-growth of the SiGe base. The SIMS analysis results of the heterostructure are shown in Fig. 1(a). The SiGe base sheet resistance measured from TLM patterns is only $705 \Omega / \square$, much lower than any reported values, which is directly resulted from using heavy base doping concentration. With a mesa-type structure used for device fabrication for which both the intrinsic and the extrinsic base regions are made on the same SiGe layer [6], such a small sheet resistance hence directly results in a small total base resistance. A uniformly distributed subcell structure (with two $2 \times 30 \mu \mathrm{m}^{2}$ emitter stripes in each subcell) is used in this power 


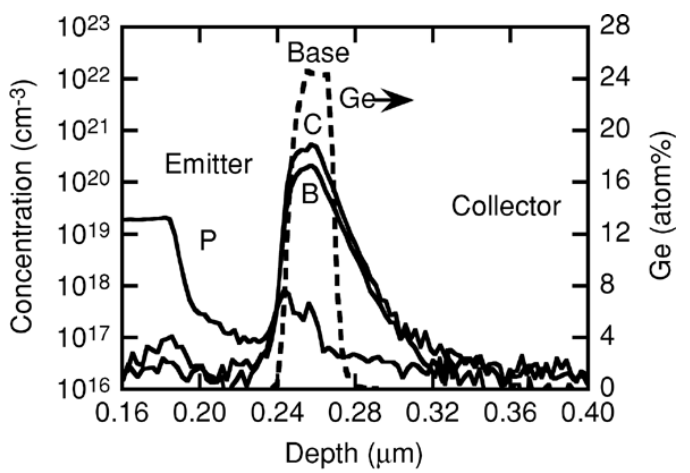

(a)

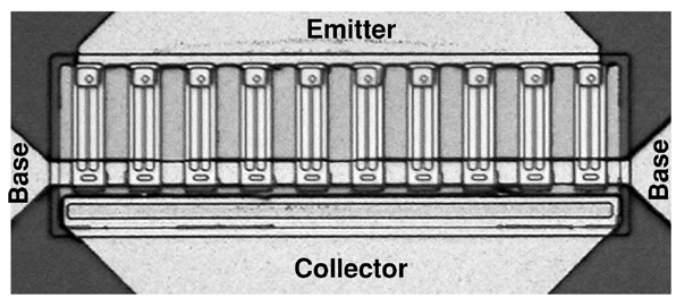

(b)

Fig. 1. (a) Measured SIMS profile for a CVD-grown Si-SiGe-Si double heterostructure. (b) Photomicrograph of a fabricated 20-emitter stripes (each of size $\left.2 \times 30 \mu \mathrm{m}^{2}\right)$ SiGe power HBT. The total emitter area is $1200 \mu \mathrm{m}^{2}$.

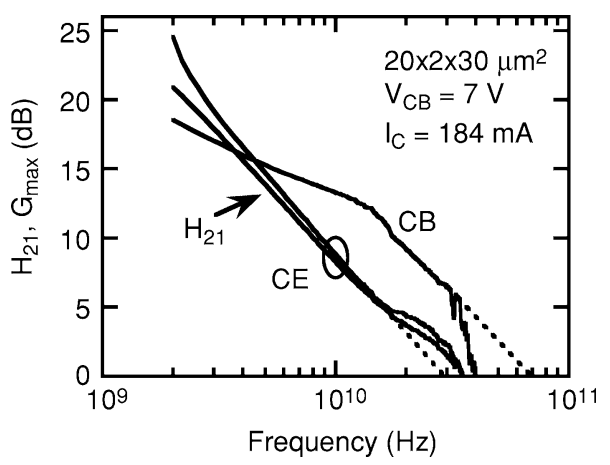

Fig. 2. $G_{\max }$ versus frequency measured for power SiGe HBTs in two different configurations. MAGs are $4.7 \mathrm{~dB}$ for the common-emitter configuration and $10 \mathrm{~dB}$ for the common-base configuration at $18 \mathrm{GHz}$ with the respective extrapolated $f_{\max }$ 's of 31 and $70 \mathrm{GHz}$, if assuming a $-20 \mathrm{~dB} /$ decade degradation trend.

device layout and detailed structure can be found in elsewhere [6]. The total emitter area of a 20-finger device is $1200 \mu \mathrm{m}^{2}$. The mesa-type power devices were fabricated from heterostructures grown on 0.5 -mm-thick Si substrates using CVD using an in-house research double-mesa process [6]. The photomicrograph of a fabricated power SiGe HBT is shown in Fig. 1(b).

\section{DeVice Performance}

High breakdown voltages are measured from the $\mathrm{SiGe}$ power HBTs with $\mathrm{BV}_{\mathrm{CBO}}=26 \mathrm{~V}$ and $\mathrm{BV}_{\mathrm{CEO}}=14 \mathrm{~V}$. The measured small-signal RF characteristics for both the $\mathrm{CE}$ and the $\mathrm{CB}$ configurations are shown in Fig. 2. The CE configuration demonstrates an $f_{T}$ of $28 \mathrm{GHz}$, resulting in an $f_{T} \cdot \mathrm{BV}_{\mathrm{CBO}}=728 \mathrm{GHz} \cdot \mathrm{V}$, comparable to the reported $\mathrm{SiGe}$ HBTs [7] having a similar $\mathrm{BV}_{\mathrm{CBO}}$. The $G_{\max }$ values at $18 \mathrm{GHz}$ are $4.7 \mathrm{~dB}$ for the $\mathrm{CE}$ and $10 \mathrm{~dB}$ for the $\mathrm{CB}$ configuration, which

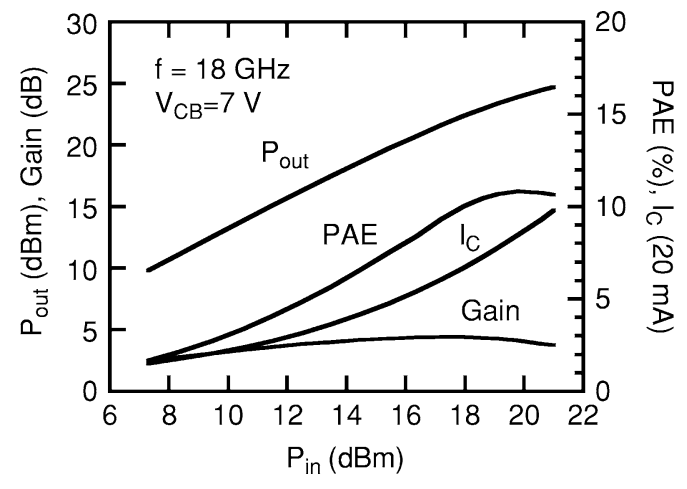

Fig. 3. Power performance of the common-base SiGe HBT biased under class $\mathrm{AB}$ operation $\left(V_{\mathrm{EB}}=-0.69 \mathrm{~V}\right.$ and $\left.V_{\mathrm{CB}}=7 \mathrm{~V}\right)$. The matching for source and load is optimized for maximum $P_{\text {out }} \cdot 24.73-\mathrm{dBm} P_{\text {out }}$ and $4.5-\mathrm{dB}$ power gain with a peak PAE of $11 \%$ were obtained.

can be extrapolated to an $f_{\max }$ value of 31 and $70 \mathrm{GHz}$, respectively, if assuming a $-20 / \mathrm{dB} /$ decade degradation trend. The relationship of $G_{\max }$ between the two configurations shown in Fig. 2 agrees well with the behavior predicted by our recent theoretical studies [8].

Since a higher $G_{\max }$ (MAG) value is available from the CB than from the $\mathrm{CE}$ configuration at $18 \mathrm{GHz}$, the $\mathrm{CB}$ configuration was then used for source/load pull power characterization. The large-signal performance of the device was tested on wafer at $18 \mathrm{GHz}$ using a Focus CCMT1816 source/load pull system. Under $\mathrm{CW}$ operation and biased at class $\mathrm{AB}$ mode $\left(V_{\mathrm{EB}}=-0.69 \mathrm{~V}, V_{\mathrm{CB}}=7 \mathrm{~V}\right)$, the device was matched for maximum output power, $P_{\text {out }}$. No oscillation was observed at any matching points during the test. Fig. 3 shows the measured output power $\left(P_{\text {out }}\right)$, power gain $(G)$, power added efficiency (PAE) and collector current as a function of input power $\left(P_{\text {in }}\right)$. The measured maximum $P_{\text {out }}$ is $24.73 \mathrm{dBm}$ with a peak PAE value of $11 \%$ and an associated power gain of $4.5 \mathrm{~dB}$. The corresponding dc power $\left(P_{\mathrm{DC}}\right)$ density of the device is $1.26 \mathrm{~mW} / \mu \mathrm{m}^{2}$ and the $\mathrm{RF}$ power density is $0.25 \mathrm{~mW} / \mu \mathrm{m}^{2}$. The power performance of the same device was also measured at lower frequencies. At $8 \mathrm{GHz}$, the measured highest RF power density is $0.56 \mathrm{~mW} / \mu \mathrm{m}^{2}$ with a PAE of $34 \%$ $\left(P_{\mathrm{DC}}=1476 \mathrm{~mW}\right)$. The lowered RF power density at $18 \mathrm{GHz}$ is ascribed to the power gain degradation with the increase of operation frequency. The degradation of power gain results in a degraded PAE $\left(=P_{\text {in }} \cdot(G-1) / P_{\mathrm{DC}}\right)$, which causes a smaller portion of the DC power being converted into RF power at the high frequency. At the two different operation frequencies, the heating power $\left(P_{\text {heat }}=P_{\mathrm{DC}} \cdot(1-\mathrm{PAE})\right)$ increased from $974 \mathrm{~mW}$ at $8 \mathrm{GHz}$ to $1351 \mathrm{~mW}$ at $18 \mathrm{GHz}$. The increased heating power thus raises the device junction temperature and further degrades the power performance of the devices. It is thus speculated that, by reducing the emitter finger width, the power gain and thus PAE values can be substantially improved. The improvement of PAE will in turn enhance the RF power levels. In spite of the large emitter width $(2 \mu \mathrm{m})$ used in the device, the overall power performance values achieved in this study are, to our knowledge, still the best among those reported SiGe power HBTs [9] and power amplifiers [7], [10] operated nearby this frequency point. For comparison, a summary of the reported RF power levels versus frequency for SiGe power 


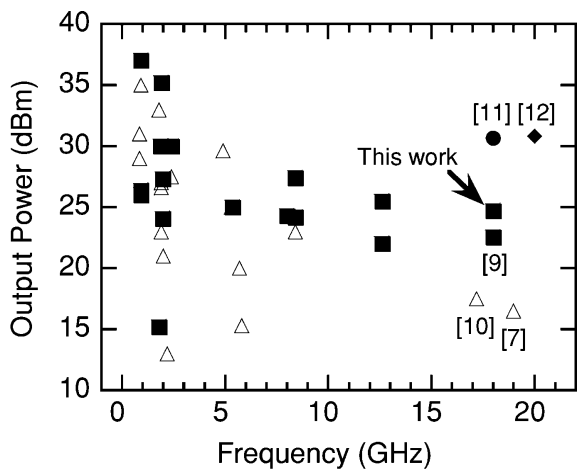

Fig. 4. Total output power versus frequency from single-chip discrete devices (square) or power amplifiers (open triangle) for SiGe HBTs. The performance results of state-of-the-art AlInAs-InGaAs-InP [11] and AlGaAs-GaAs HBTs [12] are also shown for reference.

HBTs and power amplifier modules is shown in Fig. 4 with reference to the performance of state-of-the-art InP-based [11] and GaAs-based HBTs [12]. The high performance of SiGe HBTs demonstrated here results from a low base (sheet) resistance and high device breakdown voltages. These characteristic values are realized by optimizing the device heterostructure with the goal of achieving a high $f_{\max }$ value. These optimizations also permit the CB configuration to be favorably employed at the operation frequency [8].

\section{CONCLUSION}

In conclusion, an 18-GHz, 300-mW SiGe power HBT employing a box-type $\mathrm{Ge}(24 \%)$ profile and a heavily doped $(2 \times$ $10^{20} \mathrm{~cm}^{-3}$ ) base region has been developed with the highest performance. The high $f_{\max }$ value $(70 \mathrm{GHz})$, achieved by using the optimized heterostructure, enables a higher power gain value at $18 \mathrm{GHz}$ and the lightly doped collector region enables high breakdown voltages $\left(\mathrm{BV}_{\mathrm{CBO}}=26 \mathrm{~V}\right)$, permitting high power operations. The heavy doping concentration in the base region, resulting in a low base resistance, favors the common-base configuration for power amplifications.

\section{REFERENCES}

[1] J.-S. Rieh, B. Jagannathan, D. R. Greenberg, M. Meghelli, A. Rylyakov, F. Guarin, Z. Yang, D. C. Ahlgren, G. Freeman, P. Cottrell, and D. Harame, "SiGe heterojunction bipolar transistors and circuits toward terahertz communication applications," IEEE Trans. Microw. Theory Tech., vol. 52, no. 10, pp. 2390-2408, Oct. 2004.

[2] M. Racanelli, P. Ma, and P. Kempf, "SiGe BiCMOS technology for highly integrated wireless transceivers," in Gallium Arsenide Integrated Circuit Tech. Dig., Nov. 2003, pp. 183-186.

[3] K. D. Hobart, F. J. Kub, N. A. Papanicoloau, W. Kruppa, and P. E. Thompson, "Si-Si $\mathrm{S}_{1-x} \mathrm{Ge}_{x}$ heterojunction bipolar transistors with high breakdown voltage," IEEE Electron Device Lett., vol. 16, no. 5, pp. 205-207, May 1995

[4] R. J. E. Hueting, J. W. Slotboom, A. Pruijmboom, W. B. de Boer, C. E. Timmering, and N. E. B. Cowern, "On the optimization of SiGe-base bipolar transistors," IEEE Trans. Electron Devices, vol. 43, no. 9, pp. 1518-1524, Sep. 1996.

[5] D. M. Richey, J. D. Cressler, and A. J. Joseph, "Scaling issues and Ge profile optimization in advanced UHV/CVD SiGe HBTs," IEEE Trans. Electron Devices, vol. 44, no. 3, pp. 431-440, Mar. 1997.

[6] Z. Ma, S. Mohammadi, P. Bhattacharya, L. P. B. Katehi, S. A. Alterovitz, and G. E. Ponchak, "A high power and high gain X-band $\mathrm{Si} / \mathrm{SiGe} / \mathrm{Si}$ heterojunction bipolar transistor," IEEE Trans. Microw. Theory Tech., vol. 50, no. 4, pp. 1101-1108, Apr. 2002.

[7] A. J. Joseph, J. Dunn, G. Freeman, D. L. Harame, D. Coolbaugh, R. Groves, K. J. Stein, R. Volant, S. Subbanna, V. S. Marangos, S. St. Onge, E. Eshun, P. Cooper, J. B. Johnson, J.-S. Rieh, B. Jagannathan, V. Ramachandran, D. Ahlgren, D. Wang, and X. Wang, "Product applications and technology directions with SiGe BiCMOS," IEEE J. Solid-State Circuits, vol. 38, no. 9, pp. 1471-1478, Sep. 2003.

[8] Z. Ma and N. Jiang, "On the operation configuration of SiGe HBTs based on power gain analysis," IEEE Trans. Electron Devices, vol. 52, no. 2, pp. 248-255, Feb. 2005.

[9] S. Mohammadi, Z. Ma, J. Park, P. Bhattacharya, L. P. B. Katehi, G. E. Ponchak, S. A. Alterovitz, K. M. Strohm, and J.-F. Luy, "SiGe/Si power HBTs for X- to K-band applications," in IEEE MTT-S Int. Microwave Symp. Dig., vol. 1, Jun. 2002, pp. 289-292.

[10] W. Bakalski, A. Vasylyev, W. Simbürger, R. Thüringer, H. Wohlmuth, A. L. Scholtz, and P. Weger, "A fully integrated 7-18 GHz amplifier with on-chip output balun in $75 \mathrm{GHz}-f_{T}$ SiGe-bipolar," in Proc Bipolar/BiCMOS Circuits Technology Meeting, Sep. 2003, pp. 61-64.

[11] R. S. Virk, M. Y. Chen, C. Nguyen, T. Liu, M. Matloubian, and D. B. Rensch, "A high-performance AlInAs/InGaAs/InP DHBT K-band power cell," IEEE Microw. Guided Wave Lett., vol. 7, no. 10, pp. 323-325, Oct. 1997.

[12] D. Hill, R. Yarborough, T. Kim, and H.-F. Chau, "Low thermal impedance MMIC technology," IEEE Microw. Guided Wave Lett., vol. 7, no. 2, pp. 36-38, Feb. 1997. 